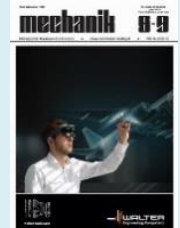

Author: Piotr Szulewski

Title of article: „Integracja informatyczna kluczowym aspektem środiwska wytwórczego w Przemysle 4.0” („IT integration is a spirit of the Industry 4.0 manufacturing environment")

Mechanik, Vol. 91, No. 8-9 (2018): pages 630-636

DOI: https://doi.org/10.17814/mechanik.2018.8-9.100

\title{
IT integration is a spirit of the Industry 4.0 manufacturing environment
}

\author{
Integracja informatyczna kluczowym aspektem \\ środowiska wytwórczego w Przemyśle 4.0
}

\section{PIOTR SZULEWSKI *}

The paper illuminates the software and technical innovations in automation industrial equipment presented at the Hannover Messe 2018: the new idea of Industry 4.0, internet of things, smart factory, communication via field buses, cobots, industrial communication.

KEYWORDS: Hannover Messe 2018, Industry 4.0, smart factory, internet of things, automation, robotics, process monitoring and supervision

At the Hanover Messe 2018, which took place on April 23-27, over 5,000 exhibitors from around the world presented themselves. In addition to well-known commercial companies, there were also 150 representatives of university start-ups who promoted their innovative ideas and solutions.

As many as $60 \%$ of companies came from 75 countries outside Germany. The fair visited a record number of 210,000 guests, and every third of them came from abroad - over 2700 viewers from Poland were registered.

In addition to traditional presentations at the stands, nearly 1,400 scientific and technical presentations and popularizing lectures were delivered. This year, the partner country was Mexico.

The motto of the exhibition was: "Integrated Industry Connect and Cooperate". Five thematic areas have been distinguished. They were:

- automation of production and processes as well as automation components,

- digitally integrated factory,

- energy, use of conventional and renewable sources,

- supply chains of materials and components for production,

- research and development and technology transfer.

Among the topics and issues discussed at presentations and conferences regarding modern automation and production automation, you can definitely choose a few currently regarded as key for development:

\footnotetext{
* Dr inż. Piotr Szulewski (maxer@cim.pw.edu.pl) - Instytut Technik Wytwarzania Politechnik Warszawskiej
}

- machine learning,

- artificial intelligence,

- industrial IT (digital production model - digital twins),

- autonomous robots supporting internal logistics operations,

- cooperation of people with robots (cobot),

- power supply and storage for electric mobile platforms (eMobility).

There is no one definition of Industry 4.0. This idea should be perceived as creating new, fully integrated production environments by means of IT systems, jointly implementing advanced production tasks [1]. In such an environment, data, technological machines, employees and their mutual communication are equally important. Only the correlation of these four components creates effective production conditions.

Referring to the thought given by Henry Ford: Joining forces is the beginning, staying together is progress, but only joint work is a success, you can determine the current stage of development of the idea of Industry 4.0 as an intense search for effective forms of its implementation in real industrial conditions.

\section{Internet of things}

IoT, IloT, AloT components are increasingly becoming components of machine tools, robots and technological devices. According to the report "Markets \& Markets loT in Manufacturing Market - Global Forecast" by 2021, the industrial Internet of Things market (IloT) will grow by an average of $27 \%$ per annum, and its value will globally exceed USD 20 billion [2]. As the main factors that have an impact on the rapid development of IloT, analysts recognize the need to take control over the production infrastructure and monitor the costs of its maintenance and performance.

In addition, according to the report "Smart Manufacturing Report 2017" [3], companies that have already implemented IIoT systems have noticed an increase in their effectiveness from 7 to even $50 \%$. Energy expenditure in such companies dropped by an average of $5 \%$, and direct costs decreased by up to $20 \%$. 
This is a real example of the effectiveness of the digitization of production processes.

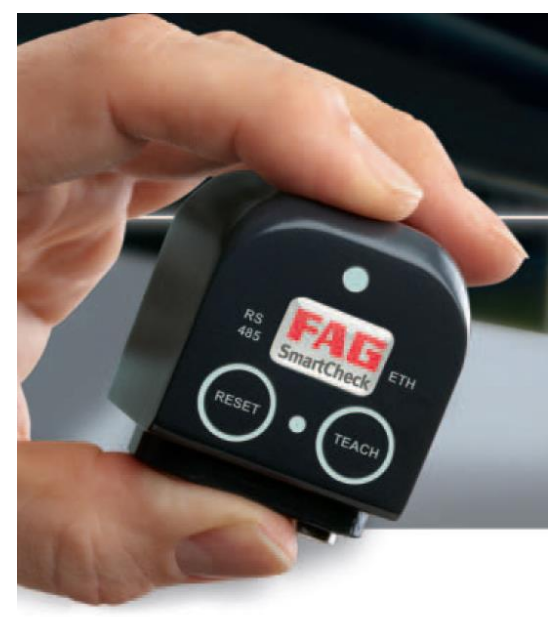

Fig. 1. SmartCheck - FAG measurement module (www.schaeffler.de)

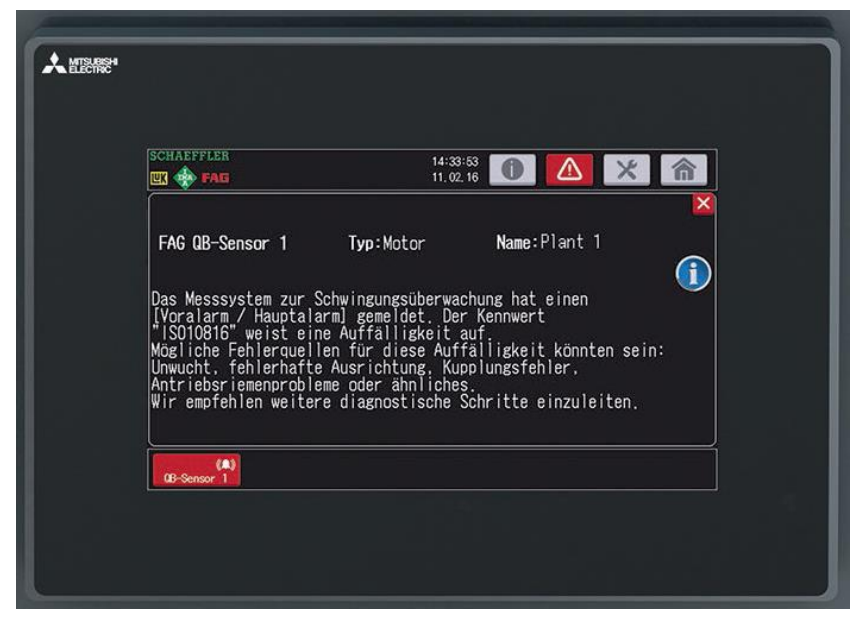

Fig. 2. SmartQB controller and SmartCheck analyzer - FAG measurement module (www.schaeffler.de)

An interesting example of implementing the idea of IloT is the measurement module from FAG (fig. 1). Although SmartCheck is intended for monitoring bearings (vibrations), due to its versatility, it can also be used in other areas (in the case of machine tools, motors, pumps, conveyor belts, etc.) [4]. The sensor used in the module allows simultaneous measurement of acceleration, speed, displacement and temperature with a resolution of 24 bits, in a wide frequency range of $0.8 \div 10 \mathrm{kHz}$. It is also possible to connect additional external measuring elements using an existing interface (analogue or digital signal). Communication with the measurement module is carried out via a network in Ethernet standard $100 \mathrm{Mbit} / \mathrm{s}$. With the web server embedded in the module, you can communicate via an ordinary browser - also via personal messengers (tablet or smartphone).

By default, the software provided by the manufacturer allows for analyzing and detecting defects or monitoring the condition of rolling bearings, unbalance of rotating masses, misalignment and impacts. The module power supply $(16 \div 32$ VDC) can be supplied from an external power supply or sent via a communication cable in the PoE standard (Power over Ethernet, IEEE 802.3af). It is also possible to work autonomously using a specialized SmartQB controller (fig. 2). Internal software (containing predefined algorithms for recognizing unfavorable phenomena, eg cavitation or unbalancing) analyzes the incoming data and presents the results of calculations in the form of clear and easy perception text messages.

\section{Machine learning}

The concept of machine learning should be understood as improving the performance of specific tasks based on experience, that is, events from the past. It is part of artificial intelligence or computational intelligence $(\mathrm{Cl})$. It consists of built-in rules and algorithms to detect anomalies or search for interesting events. Using the collected data, the system is able to accurately determine the location of disturbing symptoms and indicate their possible causes. By creating a functional model of a given device, it can also support predictive service processes. It is a form of self-learning of machines and devices. If the rule is not known, but there are "before the event" data and "after event" data (input/output), you can use the neural network to search for correlations of available data.

The most important limitation of machine learning is the fact that artificial intelligence is devoid of contextual selfawareness (so one should not expect the sense of reality to understand it) - it often finds valid schemas, but only man / operator can give them meaning. In the case of non-standard events (unique) that do not match the existing patterns, it will not be able to assess the situation effectively and it is difficult to predict its behavior [5]. This is the issue of the competence of artificial intelligence to make decisions in "transient" states.

In the last 4-5 years, a significant breakthrough in these systems has taken place. Currently, the main goal of introducing machine learning techniques in industrial conditions is to simplify the use of increasingly complex automation installations by using innovative self-learning models to free people from monotonous, repetitive or dangerous activities.

According to specialists from the Sick company, it is absolutely necessary that contemporary sensors used in diagnostic systems have built-in machine learning mechanisms. This will have a positive effect on their adaptability in changing production conditions and will significantly reduce the stream of data sent to cloud applications.

A popular example of the use of machine learning in office applications is autocorrect, commonly used in computer editing programs.

\section{Intelligent sensors}

Although the data analysis is nothing new, currently huge amounts of collected data pose difficulties in their effective transmission to computing centers [6]. For this reason, actions are being undertaken to create intelligent sensor technologies (cognitive sensor technology).

Their construction consists in the combination of three cooperating components:

- measuring element that measures one or more physical parameters of a process or object,

- measuring element that measures,

- communication interface that allows information exchange with other systems.

Fig. 3 shows the idea of an intelligent sensor. 


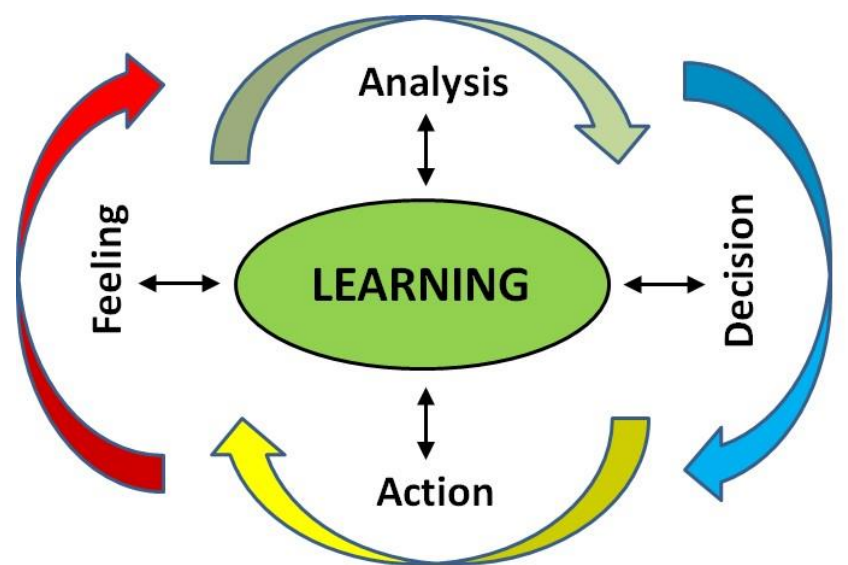

Fig. 3. Concept of using intelligent, independent sensors

In principle, such sensors are not intended for independent work, but they should create a specialized measurement network that will be characterized by very specific properties, such as:

- self-healing: based on detecting, diagnosing and reacting to disturbances in the communication network,

- self-optimization: automatic monitoring and adjustment of resources (memory, processor power, communication interface) to the changing process,

- self-configuration: dynamic change of configuration parameters in response to variable process conditions and network states,

- self-protection: prediction, detection and identification of threats and protection against threats (internal or external, accidental or malicious) coming from anywhere in the data acquisition system,

- self-service: automatic provision of services for measurement, processing and dissemination of data with the anticipation of the resources necessary for this purpose, to adapt to current requirements,

- self-awareness: self-recognition of the environment in which the sensor works; searching and generating required rules enabling cooperation with other network components,

- self-knowledge: automatic recognition of own resources (status, components, memory, communication, software updates, cooperation possibilities) that allow effective cooperation within the measurement network,

- self-maintain: continuous monitoring of the state of own resources and taking necessary remedial actions in case of prediction or occurrence of a defect.

Works on the development and development of such environments are conducted, for example, at the German Fraunhofer Institute [7].

\section{Additive production}

Additive manufacturing, otherwise known as incremental or spatial (3D) printing, is an increasingly widespread technique of creating not only prototypes but also finished products. Advanced research on this technique is carried out at many universities around the world. An example of this is the trial at the Polytechnic in Chemnitz (Germany), where for the first time a stator of a three-phase reluctance motor was made (fig. 4).

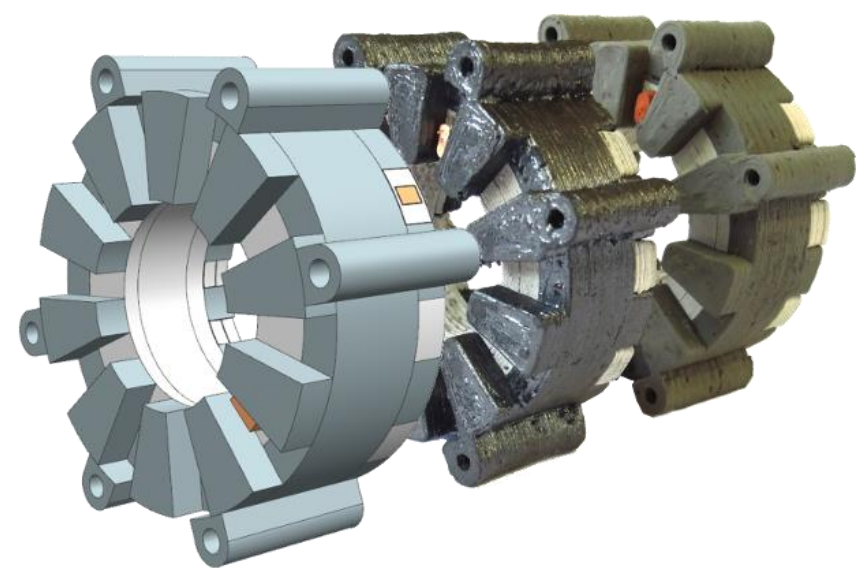

Fig. 4. Engine assembly phases in 3D printing technology (photo $\mathrm{J}$. Rudolph)

The printing process developed by the researchers included the extrusion of viscous pastes (consisting of iron, copper or ceramic particles, as well as specially adapted binding agents) and their subsequent sintering.

Thanks to the use of this new manufacturing technology, the technical limitations of the electric motor have been overcome - the maximum temperature of its operation does not exceed $220{ }^{\circ} \mathrm{C}$ because of the insulation's durability. Currently, the only limitation will be the preservation of ferromagnetic properties of iron, i.e. it becomes possible to work below $700^{\circ} \mathrm{C}$.

\section{Warning against failure}

Prediction/warning systems for an impending failure today are assembled not only in large and advanced machines, robots or industrial devices. They can be found even in electric wires (Leuze SmartCore technology) used in mobile applications (e.g. in robots, manipulators, transporters). In the wiring harness, apart from the wires for supplying and transmitting signals, there is a control line made in such a way that its lifetime is calculated for $80 \%$ of the working time of the entire wiring (harness). It is connected to the supply voltage and in case of exceeding a certain number of cycles, it is automatically interrupted which generates a warning signal in the supervisory unit (PLC) and allows for early corrective action to avoid unplanned downtime (fig. 5).

Igus is heading in a similar direction, which proposes an Igus Isense system, supporting activities related to failure prediction and facilitating service/maintenance planning (fig. 6). The product family includes sensors and monitoring modules. During the current operation, they detect the degree of wear of components such as flexible energy chains, signal cables and line modules. It is also possible to work on the network using the Igus iCOM communication module, which allows direct integration with the company's IT system.

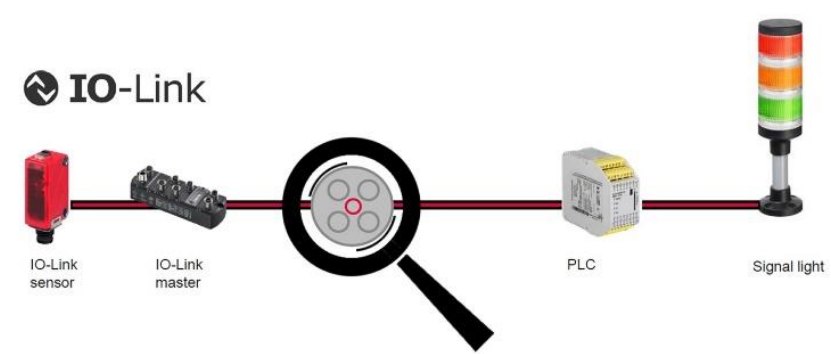

Fig. 5. Smart cable with SmartCore technology (www.leuze.com) 


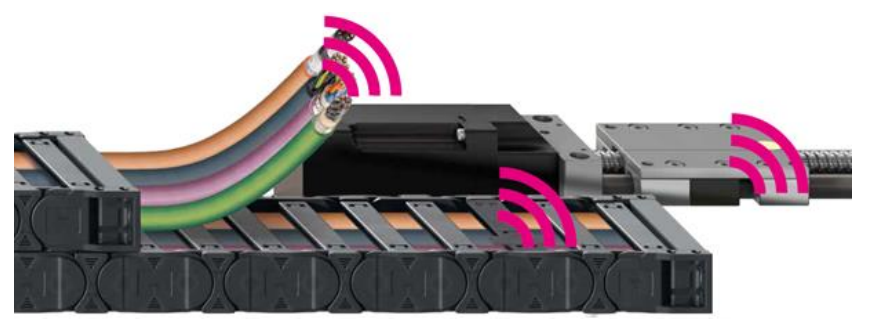

Fig. 6. Components supported by the Igus Isense platform (www.igus.com)

\section{Support systems for service and assembly activities}

Thanks to the possibilities offered by IT environments and miniaturization of electronic systems, many companies offer comprehensive support systems for activities performed by service engineers/fitters. An example is the hardware and software environment of Evolaris (fig. 7).

It consists of a headset (intelligent glasses) with a wide range of technical equipment (color display $854 \times 480,16$ MP camera, four directional microphones, satellite GPS receiver and Glonass, gyroscope, compass, WiFi and Bluetooth communication interfaces, USB, system operational Android 6 processor $2 \mathrm{GHz}, 16 \mathrm{~GB}$ Flash memory, weight $380 \mathrm{~g}$ ) and specialized software. It is the real functionality of the entire device. The Evoassist environment provides useful instructions from relational databases, shortens repair and training times, and enables experienced employees to keep up-to-date with their knowledge and activities carried out directly in the workplace.

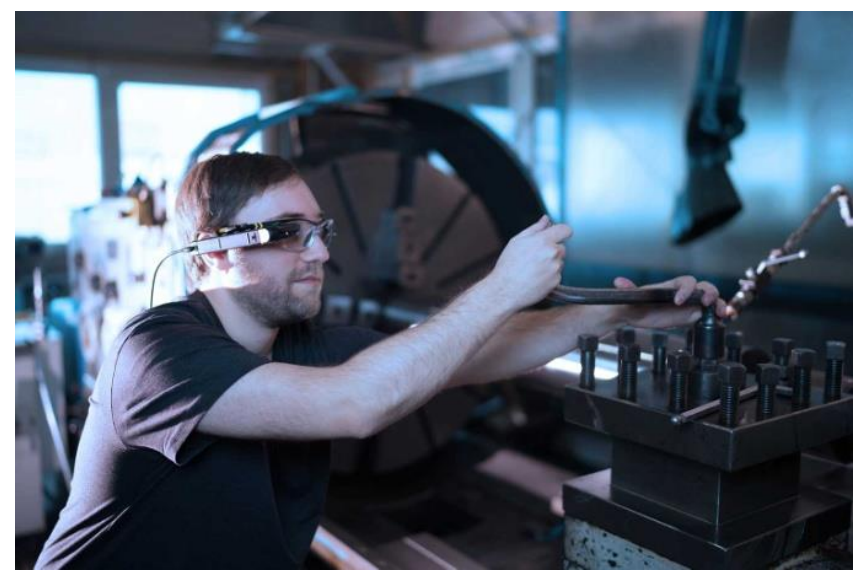

Fig. 7. Support for service activities using smart glasses (www.evoassist.evolaris.net)

\section{Industrial networks}

Communication is one of the fastest growing branches of industrial automation. It is based on industrial networks. In terms of the number of installed and active network nodes (denoting the controller, sensor or machine tool), the most widely used network standard is industrial Ethernet - in its various variants (fig. 8). Its market position is defined in total at $52 \%$ of the market with an annual growth rate of $22 \%$ [8].

In Europe, Profinet and Ethernet/IP networks are most commonly installed. This trend is most likely related to the popularization of Internet of Things (IOT) technology in devices and production machines. One should also note the very significant position of the traditional industrial network Profibus DP (12\% of installations). Radio networks (WLAN, Bluetooth and others), despite the traditionally quite conservative attitude towards wireless transmissions, are increasingly common in industrial environments. The current level of prevalence (6\%) results from a very high annual growth rate (by approx. $32 \%$ ) and is the result of the introduction of innovative architectures and forms of data exchange in automation. This is also influenced by the increasing use of machines from tablets and smartphones as information panels in workshops and machine rooms.

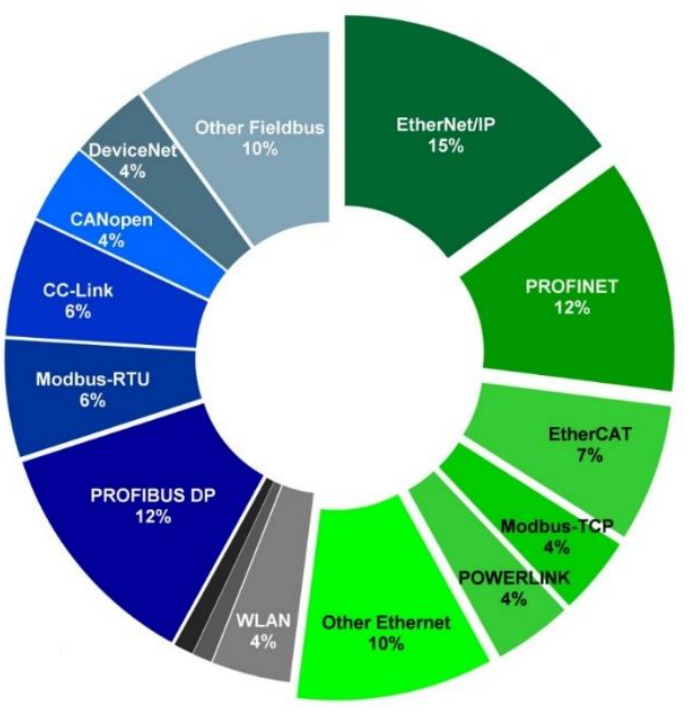

Fig. 8. Use of communication networks in industrial automation (HMS)

This is in line with the evolving BYOD concept (bring your own device) - the effective use of personal communicators as an effective alternative to traditional operator panels.

Important from the point of view of speed, efficiency and stability of IT communication in modern industrial environments is the issue of creating a unified mechanism of real-time data exchange between devices (device-todevice) and devices and cloud (device-to-cloud). An interesting concept is the application of the widespread OPC UA protocol, which enables easy and secure sharing of information in various vendor technologies, as well as a set of network standards. Work is under way on the implementation of OPC UA to the TSN (Time-Sensitive Networking) standard. This solution will be very universal due to:

- reliable delivery of data,

- guaranteed delay,

- increased availability of devices and data realizing, through IloT, analysis of large data sets and machine learning activities,

- automatic configuration and management of the communication system,

- easy compilation of the system to add subsystems and functions to existing systems, without the need to perform complex tests,

- high bandwidth and stability of work,

- the ability to connect applications and traffic in a single, open network.

Research works are carried out by a consortium (fig. 9), which includes internationally recognized companies producing advanced systems and elements of industrial automation or using them. 


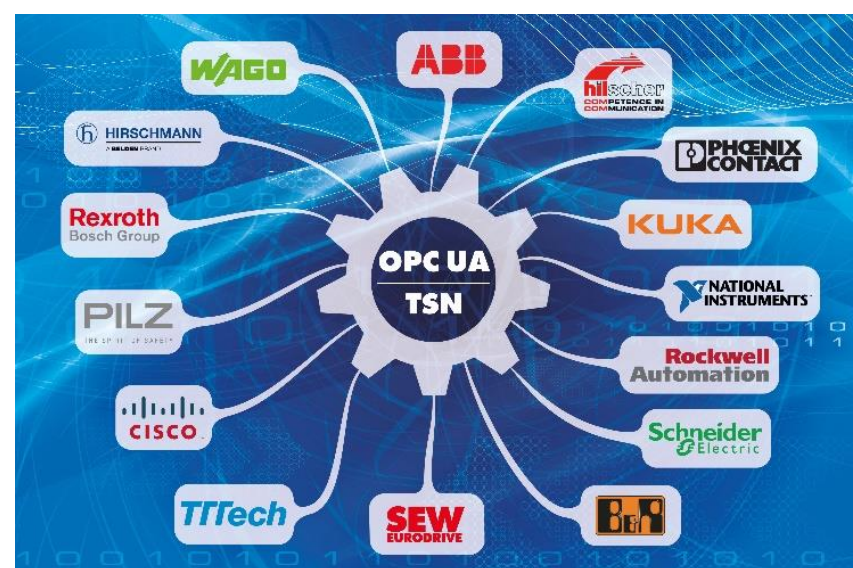

Fig. 9. Current composition of the OPC UA TSN consortium (www.rockwellautomation.com)

\section{Digital factory}

It is estimated that currently 8 billion devices are connected to the internet. By 2030, there will be a trillion of them. It is necessary to create a safe IT environment (cloud) in which companies will have complete control over their own data and will be able to use them freely to intelligently create innovative services. The proper use of information gathered in information monitoring systems becomes a more and more serious issue. Their enormous number, complexity and interpenetration of content significantly hinder their processing and analysis.

Approximately: 2.5 billion $G B$ is created daily. It is estimated that about $90 \%$ of all data generated in the world ever was created in the last two years. On the other hand, only $1 \%$ of information is subject to real analysis [9]. One can risk a hypothesis that this is a real challenge that must be worked on, because the "ocean" of data provides answers to the problems we will face in the near future.

Siemens recognizes the complexity of this issue. The software environment developed by her covers all stages of the production chain, i.e.: construction of the object / machine tool, preparation of the production, machining, assembly and start-up as well as service support.

The structural concept of program support is presented in fig. 10. According to it, three competence areas were distinguished: "On the machine", "On production", "In the cloud". In order to provide the appropriate scope of IT support, three cooperating platforms are proposed: MindSphere, SINUMERIK Integrate and SINUMERIK/SINUMERIK Edge. They offer a number of functions - from the machine level to cloud solutions. They allow you to create new business models, for example in the field of maintenance services. Thanks to digitalization, you can get advances in optimization and use it to increase productivity and competitiveness.

GM, Fanuc and Cisco promote their ZDT (Zero Down Time) solution. It means striving for zero time of machine tools and the entire machinery park. This is done using cloud computing technology used to analyze data collected by working robots to detect potential risks associated with downtime. According to research, one minute of downtime of the assembly line in the automotive industry is about USD 20,000 additional costs.

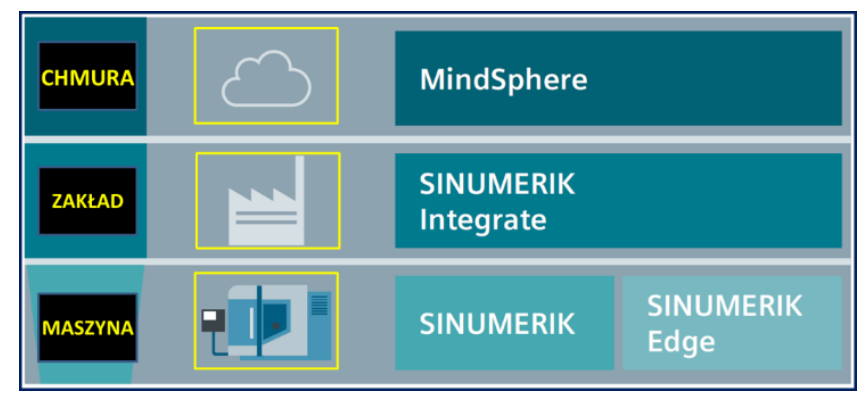

Fig. 10. Components of the digital factory information environment (www.siemens.com)

The ZDT program is part of the FIELD system (Fanuc Intelligent Edge Link and Drive) - intelligent connection and control of edge devices (robots, CNC, drives, sensors). The concept is to transfer advanced data analysis and machine learning to the edge of the network. This results in a significant reduction in transmission delays and the ability to react to events in real time.

A well-known robot manufacturer - Kuka - is in a similar direction, offering its Kuka Connect platform. It is a powerful software tool for the current analysis of data obtained directly from robots in real time. The goal is to calculate specific key performance indicators for a given device (KPI - key performance indicators) to support maintenance work related to maintenance. An example is the precise observation of the temperature of the selected robot axis. The rapid increase in the value of this parameter may indicate an impending gear failure or an excessive load of the object.

Also large IT corporations, such as Hewlett Packard, offer their own solutions for the industry, enabling the processing of large volumes of data directly at the edge of their creation (edge computing), without the need to involve cloud and transfer technologies. Integrated data processing centers equipped with high-performance processor clusters and dedicated software are proposed. They are prepared for direct installation in the workshop. They are completely autonomous environments with software and hardware security (e.g. backup power).

\section{Voice communication}

Industry 4.0 is in principle a system of perfectly harmonized elements, in which machine tools, technological machines, robots and people together create a new production environment. An interesting issue is to allow people / operators to communicate with machines using voice. This form has many advantages and seems to be a natural direction for the development of automatic surveillance systems.

It is worth recalling that 20 years ago, Nuance's speech recognition system could distinguish 20 words, and now systems know many millions of them in different languages.

The Beckhoff company proposed a specialized TwinCat Speech module, which is a component of the extended TwinCat 3.0 programming environment (fig. 11). 


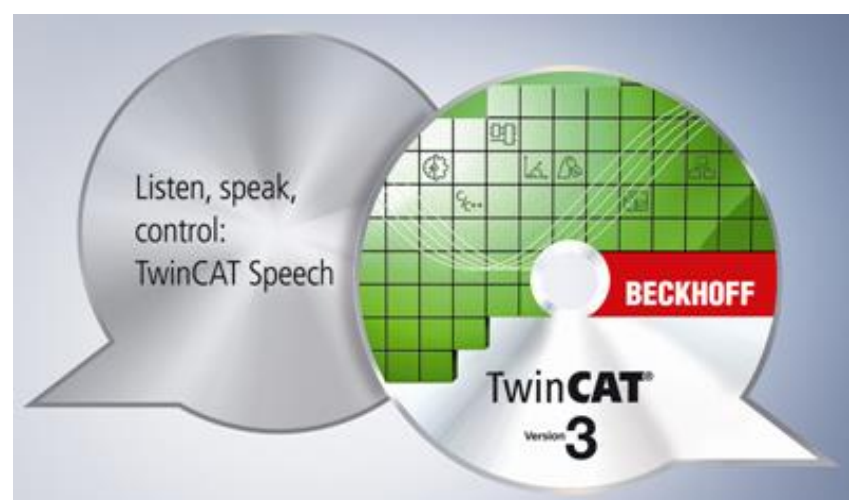

Fig. 11. TwinCat Speech voice communication module (www.beckhoff.com)

It enables multilingual input/output of information in accordance with industry standards. Due to this interaction with the automation system is much more efficient and convenient. The use of speech recognition is available offline (no need to connect to the internet or cloud), based on the built-in functions of the Windows operating system. Voice synthesizing (using the selflearning function) is available both offline and online (via Amazon's Polly text-to-speech conversion service).

Lenze Drives introduces a similar solution. The new line of drive controllers (i950 servo drive) allows to carry out diagnostics using voice commands. The Alexa speech recognition system from Amazon is used, for example in the smartphone's personal devices. The communication of operators with industrial automation devices will increasingly remind you of a casual conversation and relieve the operator of having to focus on visual messages and using a computer keyboard.

\section{Robots}

Increasing the number of robots in the technological process is one of the main methods of achieving the growth of automation. With a view to reducing the costs of mass manufacturing robots, lgus offers an innovative modular motion system - the Apiro robot (fig. 12). Its

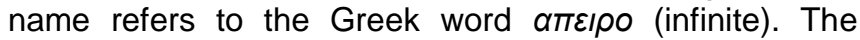
system consists of elements with different kinematic systems: rotary, feed and parallel, which allow the creation of Scara, articulated and humanoid robots. It is possible to attach various gears, and all moving parts are made in self-lubricating technology and are resistant to dirt. Low weight (due to the use of aluminum profiles), resistance to chemicals and a long service life allow you to work freely without having to bear the costs of renovation and maintenance.

Cooperating robots determine the direction of common use of devices cooperating with a human (operator). The condition for their effective introduction is the use of special sensors and control methods related to the theory of cognitive machines (cognitive machines). The aim is to enable the robots to independently and actively recognize the environment (sharing the workspace) and to analyze their activities to eliminate exceptional situations - which is indispensable to ensure their safe contact with people.

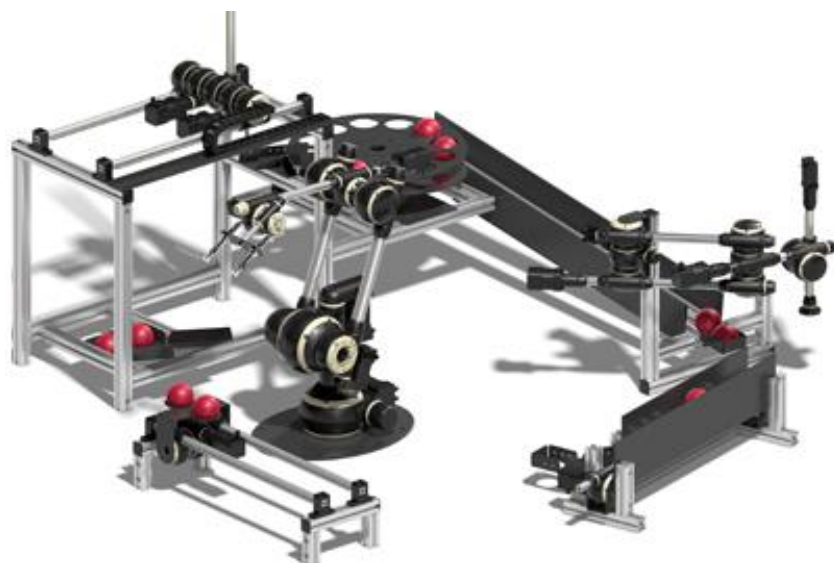

Fig. 12. Modular traffic system - Apollo robot (www.igus.com)

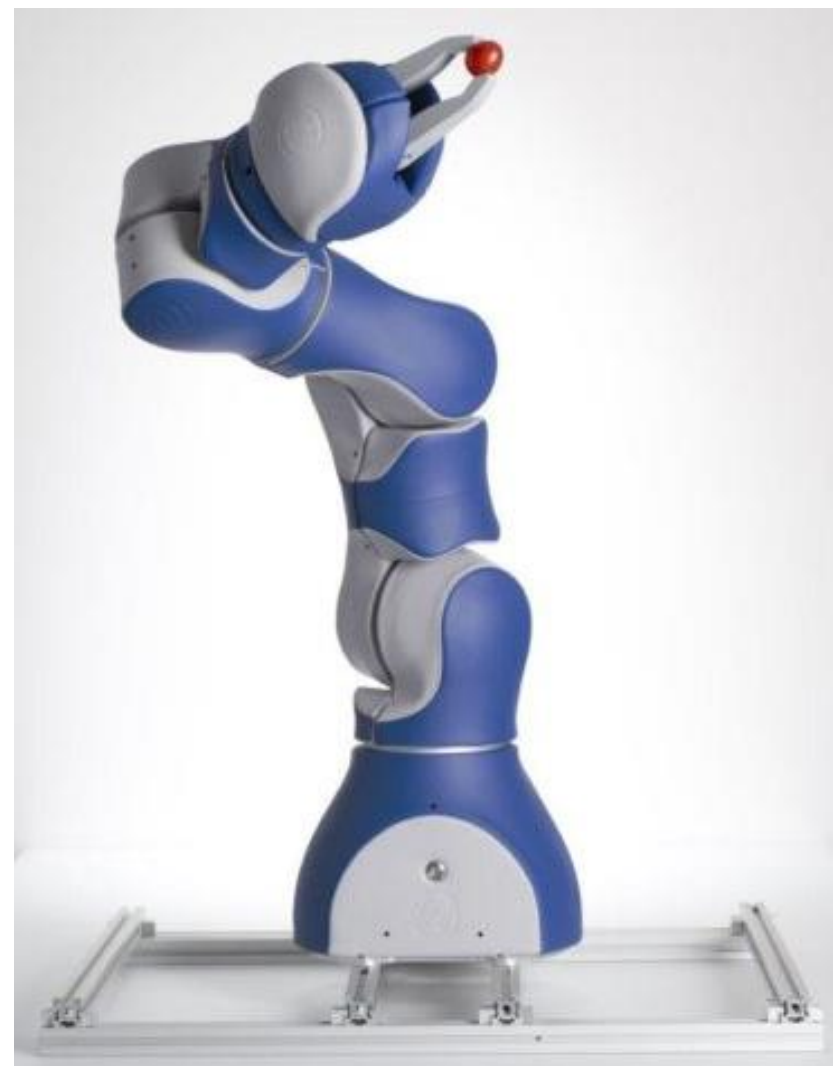

Fig. 13. Cooperating robot P-Rob (www.fp-obotics.com)

Basic criteria are set to help engineers in making decisions about the use of such robots in the factory practice, including:

- profitability of the entire undertaking,

- activities with the robot must be part of the planned work,

- before starting cooperation it is necessary to start / activate available security systems,

- robot must normally be equipped with human assistance functions in accordance with ISO 10218.

An example of this is the light and economical cooperating robot from P-Rob from the Swiss company F\&P Robotics AG (fig. 13). All P-Rob models offer a positioning repeatability of $0.1 \mathrm{~mm}$ and a payload of up to $3 \mathrm{~kg}$. The shoulder covers are made of a soft shell combined with synthetic leather. It protects both operators and the construction of the robot from damage. The interchangeable P-Grip handles combined with myP software enable easy integration of sensors and vision systems. Thanks to them, P-Rob is aware of his work environment. He learns objects (shapes, hardness, 
orientation) with the help of many sensors, takes into account changes in space and adapts his behavior.

\section{Drives}

Electric motors are the basic unit of every machine. The dynamic properties of the entire drive depend on their efficiency, power and torque characteristics. One of the directions of searching for new solutions is the study of the possibility of using superconductors in the construction of drive motors. Maintenance of the superconducting material at a suitably low temperature (usually approx. $70 \mathrm{~K}$ ) results in reaching zero resistance to the current flow, i.e. no adverse power losses and an increase in the motor temperature.

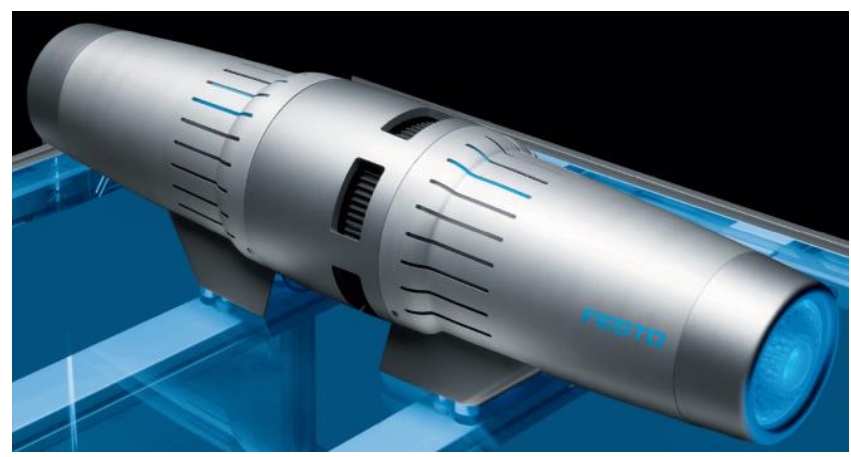

Fig. 14. Prototype of a superconducting industrial engine (www.festo.com)

Thanks to this, it is possible to create a very strong magnetic field using very high current values. This is particularly important at low speeds (with high torque) and also when the engine needs to be stopped under full load.

The superconductor motor model (SupraMotor) presented by Festo with solid cooling (fig. 14) is now a study model. According to the information provided by the company at a useful engine power of several dozen kilowatts, the power necessary to maintain its correct temperature is less than 5 $\mathrm{W} /$ winding. The prototype works with low current values due to the limitations of the magnetic flux density that ferromagnetic materials can adopt. The benefits of using superconductor drives are unmistakable and it should be expected that this concept will set research directions for the coming years.

\section{Exoskeleton}

According to the Federal Institute for Safety and Health at Work, injuries to the musculoskeletal system are the reason for using $23 \%$ of disease days in Germany and lead to an estimated gross loss of EUR 17 billion per year. The main causes of these diseases are physical loads when lifting and moving at work, causing damage to muscles, ligaments, bones and cartilage. In some cases, popular static aids, such as forklifts or davits, cannot be used or are not flexible enough.

Then, the Bionic CRAY $X$ exoskeleton might be helpful (fig. 15). It is designed in such a way as to reduce the pressure/compression of the lower back and thus protect the user against injuries to this part of the skeleton. It provides posture support when positioning or operating tools, objects, etc. The design uses new micromechanical elements and an ultra-light, ergonomic bearing system. In the future, the retrofitting of the structure with a sensory data transmission system is expected, which will enable the introduction of machine learning and artificial intelligence to the exoskeleton controller.

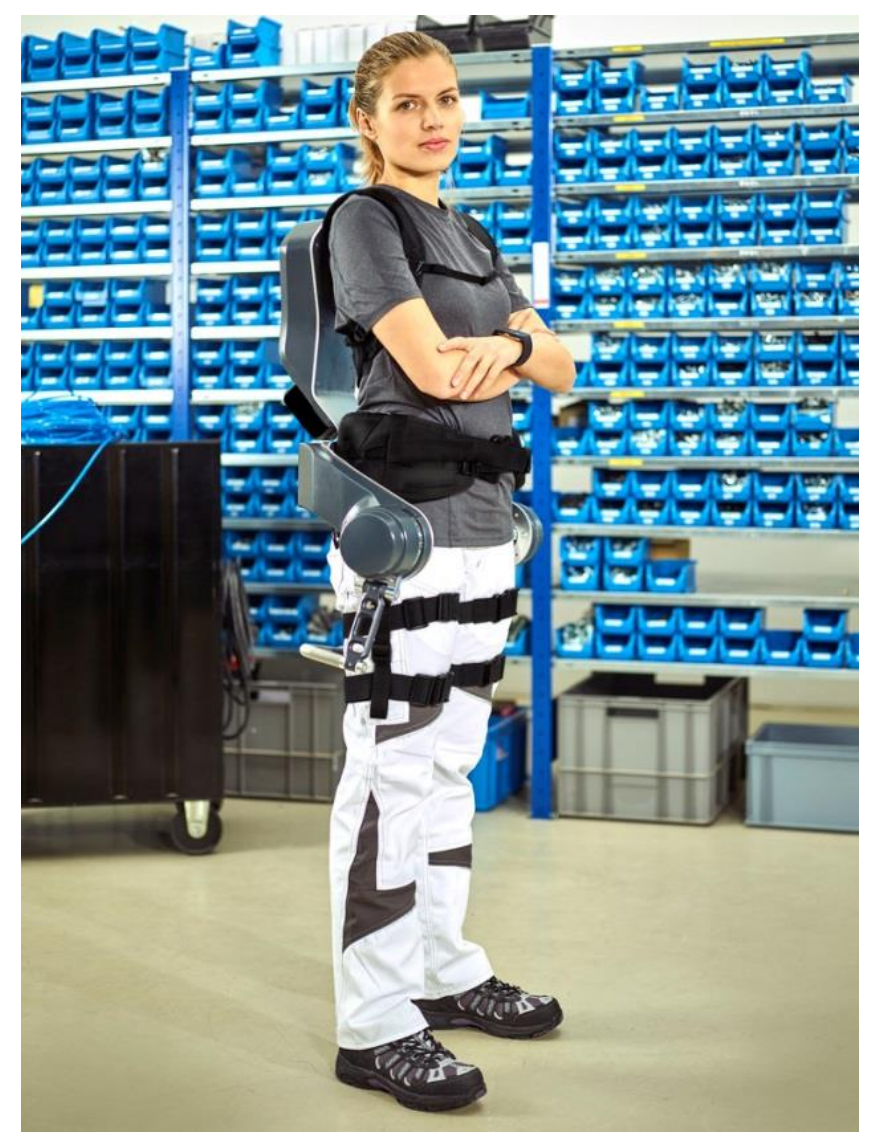

Fig. 15. Exercise worn by Bionic CRAY X (www.germanbionic.com)

\section{Conclusions}

It seems that the directions of development of modern automation are already defined. All-encompassing computerization and effective communication are aimed at creating a completely digital production model. However, existing manufacturing environments do not allow for quick and low-budget implementation of this idea. The varied level of automation of individual technological machines and the very high cost of modern machine tools force us to look for an effective method of implementing the idea of a digital factory in the production environment available to us [10]. In this area, the most intense work takes place.

Next edition of the Hannover Messe will take place on 1. 5 April 2019, and the partner country of the exhibition will be Sweden.

\section{REFERENCES}

1. Szulewski P. „Efektywne łączenie systemów podstawą inteligentnej produkcji”. Mechanik. 1 (2018): pp. 7-11.

2. www.marketsandmarkets.com/PressReleases/smart-factory.asp.

3. https://altizon.com/smart-manufacturing-report-2017/.

4. www.schaeffler.com/remotemedien/media/ shared media/08 m edia_library/01_publications/schaeffler_2/tpi/downloads_8/tpi_21 4_de_en.pdf.

5. Domingos P. "A Few Useful Things to Know about Machine Learning". Washington: University of Washington, 2012, https://pdfs.semanticscholar.org/b4cc/7906b32205f6723b3 deee6ddcce32926d2fd.pdf.

6. Śniegulska-Grądzka D., Szulewski P. „Systemy automatycznego monitorowaniadrgań w obrabiarkach". Mechanik. 3 (2017): pp. 170-175.

7. https://www.iis.fraunhofer.de/en/magazin/kognitivesensorik.html.

8. https://www.hms-networks.com/press/2018/02/27/industrialethernet-is-now-bigger-than-fieldbuses. 
9. Henke N., Libarikian A., Wiseman B. "Straight Talk about Big Data",2016, https://www.mckinsey.com/business-

functions/digital-mckinsey/our-insights/straight-talk-about-bigdata.

10. Szulewski P. „Industry $4.0-w$ kierunku inteligentnego wytwarzania".Mechanik. 1 (2017): pp. 60-65.

Translation of scientific articles, their computer composition and publishing them on the website www.mechanik.media.pl by original articles in Polish is a task financed from the funds of the Ministry of Science and Higher Education designated for dissemination of science.

Ministry of Science and Higher Education

Republic of Poland 